\title{
Ongoing outbreak of West Nile virus infections in humans in Greece, July - August 2010
}

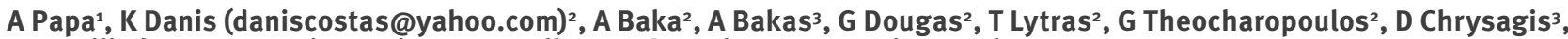

E Vassiliadou ${ }^{3}$, F Kamaria ${ }^{3}$, A Liona ${ }^{2}$, K Mellou ${ }^{2}$, G Saroglou ${ }^{2}$, T Panagiotopoulos $^{2,4}$

1. Reference Laboratory for Arboviruses, First Department of Microbiology, Medical School, Aristotle University of Thessaloniki, Thessaloniki, Greece

2. Hellenic Centre for Disease Control and Prevention (KEELPNO), Athens, Greece

3. Department of Internal Medicine, Infectious Disease Hospital, Thessaloniki, Greece

4. National School of Public Health, Athens, Greece

Citation style for this article:

Papa A, Danis K, Baka A, Bakas A, Dougas G, Lytras T, Theocharopoulos G, Chrysagis D, Vassiliadou E, Kamaria F, Liona A, Mellou K, Saroglou G, Panagiotopoulos T. Ongoing outbreak of West Nile virus infections in humans in Greece, July - August 2010. Euro Surveill. 2010;15(34):pii=19644. Available online: http://www.

eurosurveillance.org/ViewArticle. aspx?Articleld =19644

Between early July and 22 August 2010, 81 cases of West Nile neuroinvasive disease were reported in the region of Central Macedonia, northern Greece. The median age of cases was 70 years. Encephalitis, meningoencephalitis or aseptic meningitis occurred mainly in patients aged 50 years or older. This is the first time that West Nile virus (WNV) infection has been documented in humans in Greece. Enhanced surveillance and mosquito control measures have been implemented.

\section{Introduction}

On 4 August 2010, physicians from the Infectious Disease Hospital in Thessaloniki, northern Greece, informed the Hellenic Centre for Disease Control and Prevention (KEELPNO) about an increase in the number of hospitalised cases with encephalitis in the previous month (13 patients with encephalitis were hospitalised in July 2010, compared with a mean of five hospitalised cases in the same month of the previous three years). Despite several laboratory tests, no aetiological factor had been identified. Most patients were elderly (over 65 years of age) and resided in the region of Central Macedonia, northern Greece. On the same day, 11 serum and three cerebrospinal fluid (CSF) specimens from 11 patients with encephalitis and/or aseptic meningitis were sent for further testing to the Reference Laboratory for Arboviruses at the Aristotle University of Thessaloniki. The following day, the results showed that IgM antibodies against West Nile virus (WNV) had been detected in 10 of the 11 serum specimens and in all three CSF specimens. WNV infection in humans had not been previously documented in Greece.

WNV is a positive-sense RNA virus of the Flaviviridae family, belonging to the Japanese encephalitis antigen group of viruses [1]. WNV is maintained in an enzootic cycle between birds and mosquitoes, mainly Culex species, while humans, horses and other mammals are incidental or dead-end hosts. Most human WNV infections are subclinical, and approximately $20 \%$ of infected individuals develop a febrile illness, while in less than $1 \%$, the disease progresses to neuroinvasive disease, with the most severe form seen among elderly and immunocompromised individuals [2].

Although the virus was first isolated in 1937, interest in its impact on humans increased in 1996, when a large outbreak of West Nile neuroinvasive disease (WNND) was observed in Romania and in 1999, when WNV was introduced into the United States [3,4]. Several cases of WNV infection have been reported in horses and humans in Mediterranean countries [5-8], while WNND has been recently reported in humans in Hungary and Italy [7-9].

\section{Methods}

Surveillance

Following an alert issued by the Ministry of Health and KEELPNO on 6 August 2010 about 11 reported WNV infection cases, physicians in Greece were asked to notify KEELPNO of all confirmed or probable cases of WNV infection using a standardised reporting form, which included information on the demographic characteristics, clinical manifestations, underlying chronic medical conditions, potential risk factors and laboratory results of cases. The exact address of cases' place of residence was obtained from hospital registries. In addition, active surveillance to identify cases included daily telephone inquiries to the hospitals of the region of Central Macedonia, from where the cases had been reported.

\section{Case definition}

The 2008 European Union case definition of WNV infection [10] was used, with slight modifications. A confirmed case was defined as a person meeting any of the following clinical criteria: encephalitis, meningitis, fever without specific diagnosis and at least one of the four laboratory criteria: (i) isolation of WNV from blood or CSF, (ii) detection of WNV nucleic acid in blood or CSF, (iii) WNV-specific antibody response (IgM) in CSF, 
and (iv) WNV IgM high titre, and detection of WNV IgG, and confirmation by neutralisation.

A case was considered probable if the patient met the above clinical criteria and a WNV-specific antibody response was demonstrated in his or her serum sample. Epidemiological criteria were not used in the case definition due to the absence of recent surveillance data in animals.

\section{Laboratory methods}

Serum and CSF specimens were tested for the presence of WNV-specific IgM and IgG antibodies using commercial ELISA kits (Focus Technologies, Cypress, CA, USA). Reverse transcription-polymerase chain reaction (RT-PCR) was performed on RNA from 15 of 99 specimens, because the remaining samples had been taken between three and 15 days after the onset of illness, when viraemia is usually over. Primer sets specific for WNV and degenerate primers (able to detect flavivirus RNA) were used [11,12].
Data analysis

Data were entered in a database designed using Epidata software (Epidata association, Denmark, version 3.1) and were analysed using the GNU R software environment. Incidence was calculated using the 2007 mid-year estimated population from the Hellenic Statistical Authority as denominator [13].

\section{Results}

By 22 August 2010, 99 cases of WNV infection had been notified to KEELPNO. Of these, 81 had central nervous system manifestations (West Nile neuroinvasive disease, WNND) and 18 (eight probable and 10 confirmed cases) had only mild symptoms of fever and headache. We analyse here the 81 cases of WNND. Of these, 39 were confirmed and 42 were probable cases. The overall incidence of WNND was 0.72 cases per 100,000 population.

In total, 77 serum and 47 CSF specimens were available; for 45 of the 81 WNND patients both CSF and serum specimens were provided, while for four patients only CSF was available. WNV-specific IgM antibodies were detected in all 77 serum and in 39 of the 47 CSF specimens, while WNV-specific IgG antibodies were detected

\section{FIGURE 1}

Reported cases of West Nile neuroinvasive disease by date of symptom onset, Greece, 1 July - 22 August 2010 (n=81)

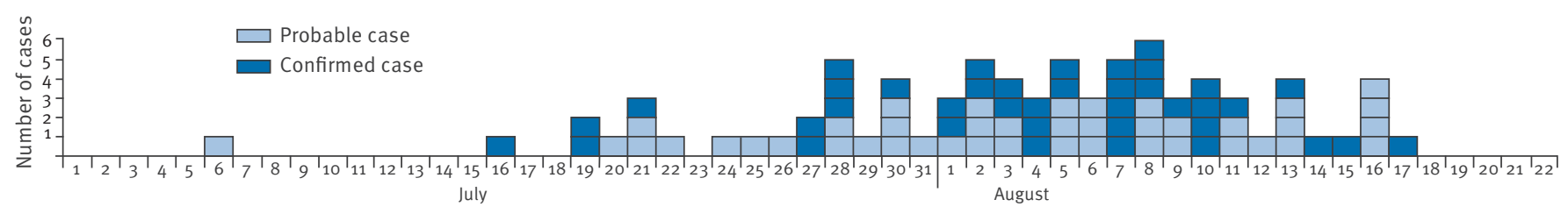

Date of symptom onset, 2010

TABLE 1

Characteristics of reported cases of West Nile neuroinvasive disease, Greece, 1 July - 22 August 2010 (n=81)

\begin{tabular}{|c|c|c|c|}
\hline Characteristic & Number of cases & Incidence (per 100,000 population) & Risk ratio $(95 \% \mathrm{Cl})$ \\
\hline $\begin{array}{l}\text { Age group (years) } \\
<20 \\
20-29 \\
30-39 \\
40-49 \\
50-59 \\
60-69 \\
70-79 \\
\geq 80 \\
\text { Sex } \\
\text { Female } \\
\text { Male } \\
\text { District (prefecture) of residence } \\
\text { Thessaloniki } \\
\text { Imathia } \\
\text { Kilkis } \\
\text { Pella } \\
\text { Pieria } \\
\text { Serres } \\
\text { Larisa }\end{array}$ & $\begin{array}{c}3 \\
3 \\
2 \\
2 \\
12 \\
14 \\
37 \\
8 \\
\\
\\
36 \\
45 \\
\\
\\
27 \\
21 \\
9 \\
17 \\
2 \\
3 \\
2 \\
\end{array}$ & $\begin{array}{l}0.14 \\
0.20 \\
0.11 \\
0.12 \\
0.85 \\
1.18 \\
3.49 \\
1.79 \\
\\
\\
0.64 \\
0.81 \\
\\
\\
2.37 \\
14.57 \\
10.44 \\
11.72 \\
1.56 \\
1.59 \\
0.70\end{array}$ & $\begin{array}{c}\text { Reference } \\
1.44(0.96-10.95) \\
0.83(0.18-7.37) \\
0.90(0.29-9.85) \\
6.16(1.93-29.40) \\
8.56(1.29-33.72) \\
25.39(6.92-101.72) \\
13.05(2.81-43.94) \\
\\
\text { Reference } \\
1.27(0.92-3.24) \\
\\
\text { Reference } \\
6.15(1.32-11.64) \\
4.44(1.29-12.34) \\
4.95(2.12-8.14) \\
0.66(0.32-5.43) \\
0.67(0.17-3.25) \\
0.30(0.12-1.85)\end{array}$ \\
\hline Total (in country) & 81 & 0.72 & - \\
\hline
\end{tabular}

$\mathrm{Cl}$ : confidence interval. 
in 42 of the 77 serum and 17 of the 47 CSF specimens. In 39 of the 45 patients for whom both types of specimen were available, the presence of IgM in both CSF and serum was seen, proving autochthonous antibody production; for IgG this was not tested. As crossreactions are common among flaviviruses, specimens were also tested for tick-borne encephalitis (TBE) virus (although TBE is not prevalent in the area and none of the patients reported tick bites): all were negative. Low cross-reactivity was seen with dengue virus; however, when a positive result was obtained for dengue virus, the titres were very low compared with the high titres seen for WNV. None of the patients had been vaccinated for yellow fever. RT-nested PCR was negative in all specimens tested.

The first cases of WNND had onset of symptoms in early July (Figure 1).

\section{FIGURE 2}

Place of residence of reported cases of West Nile neuroinvasive disease, Greece, 1 July - 22 August $2010(n=80)^{\text {a }}$

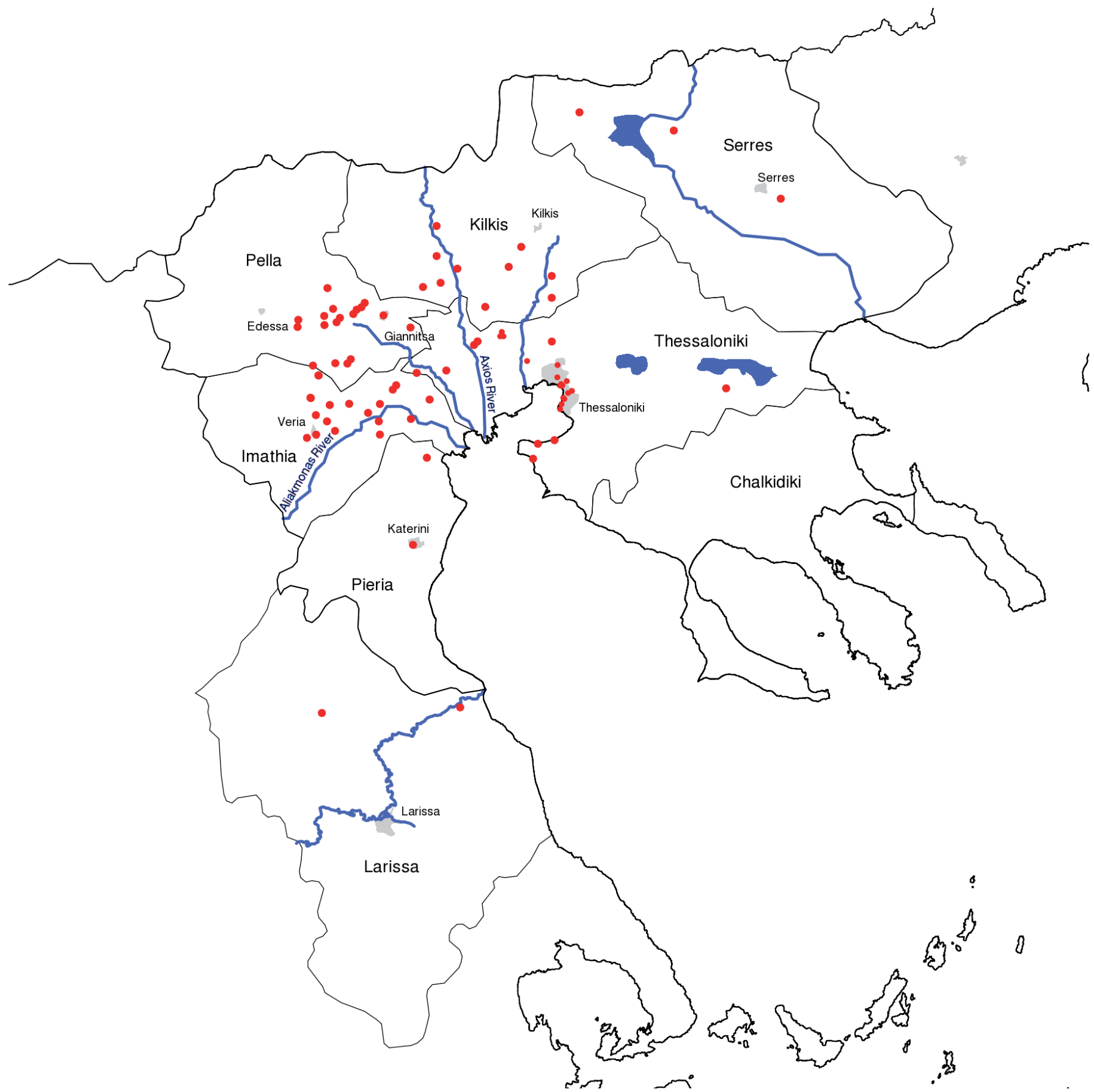

${ }^{a}$ For one of the 81 cases of West Nile neuroinvasive disease, the place of residence has not been confirmed and is not included on the map. Each dot represents one case; the grey areas represent towns or cities; the blue lines represent rivers.

The district of Larissa belongs to the region of Thessalia. All other districts from where cases have been reported belong to the region of Central Macedonia. 
The median age of the WNND cases was 70 years (range: $12-86$ years), with most $(n=71)$ aged 50 years or older (Table 1). Of all WNND cases, 45 (56\%) were males.

The incidence, 1.7 per 100,000 population, of WNND among those aged 50 years or older was almost 12 times higher (risk ratio: 12.2; 95\% confidence interval: 4.9 to 28.5 ) than that of individuals aged under 50 years. The risk of WNND was $27 \%$ higher among males compared with females (Table 1 ).

The place of residence of the WNND cases is presented in Figure 2: 30 resided in an urban area and 51 in a rural setting. The vast majority $(n=79)$ lived in districts (prefectures) of the region of Central Macedonia and only two were reported from the region of Thessalia (district of Larissa). It is of note that a large number of cases $(n=58)$ lived near rivers and/or on the irrigated plains between and surrounding the Aliakmonas and Axios rivers (Figure 2).

None of the notified cases reported travel to a known WNV-endemic area during the two weeks before onset of symptoms. Information on outdoor activities was gathered from 55 of the cases: 27 cases reported spending many hours outdoors in the countryside every day. None of the cases had a history of blood transfusion or tissue/organ transplant during the two weeks before the onset of symptoms.

All notified cases with central nervous system manifestations were hospitalised. Of those, 65 had encephalitis or meningoencephalitis, and 16 had aseptic meningitis (Table 2).

Of the 65 WNND cases with encephalitis and/or meningoencephalitis, 60 were aged 50 years or older.

\section{TABLE 2}

Clinical manifestations of reported cases of West Nile neuroinvasive disease by age group, Greece, 1 July - 22 August $2010(\mathrm{n}=81)$

\begin{tabular}{|l|c|c|}
\hline Age group (years) & $\begin{array}{c}\text { Number of cases with } \\
\text { encephalitis or } \\
\text { meningoencephalitis }\end{array}$ & $\begin{array}{c}\text { Number of cases with } \\
\text { aseptic meningitis }\end{array}$ \\
\hline $20-29$ & 1 & 2 \\
$30-39$ & 1 & 1 \\
$40-49$ & 1 & 1 \\
$50-59$ & 9 & 3 \\
$60-69$ & 13 & 1 \\
$70-79$ & 31 & 6 \\
$\geq 80$ & 65 & 16 \\
\hline Total & 2 & 1 \\
\hline
\end{tabular}

Information on underlying chronic medical conditions was available for 60 of the 81 patients. These included hypertension $(n=26)$, a history of immunosuppresion $(n=17)$, coronary artery disease $(n=11)$, and diabetes mellitus $(n=9)$. Ten cases were admitted to an intensive care unit. As of 22 August 2010, eight cases had died, giving a case fatality rate of $9.9 \%$ among the reported WNND cases. All deceased patients were aged over 70 years, and suffered from hypertension and diabetes.

\section{Discussion and conclusions}

We describe here 81 cases of WNND reported between early July and 22 August in the region of Central Macedonia, northern Greece. The fact that a small proportion of infected individuals develop WNND [2] suggests that this ongoing outbreak may in fact be larger. As of 26 August 2010, more cases of WNND have been reported bringing the total number of WNND cases to 108. In addition, information was gathered through enhanced surveillance, and a degree of under-reporting, particularly at the beginning of the outbreak, is expected.

Serological surveys conducted in humans in the $1980 \mathrm{~s}$ and in 2007 in Greece identified WNV antibodies in approximately $1 \%$ of selected populations (i.e. farmers, wood-cutters, shepherds) in the region of Central Macedonia. Of 392 serum samples collected from residents in a selected urban area in the district of Imathia (central Greece) in 2007, six were positive for WNV, of which four were confirmed by microneutralisation assay $[14,15]$. The authors concluded that WNV or related viruses circulate in endemic cycles in rural areas in Greece. In contrast, a survey of 9,590 blood donations and 115 CSF samples from patients with aseptic meningitis in Greece between 2005 and 2007 revealed no positive results for WNV by nucleic acid test. However, the sources of the clinical samples were major laboratories and/or blood banks in the cities of Athens and Ioannina [16].

The presence of WNV in animals is not monitored routinely in Greece. However, a few ad-hoc studies have been conducted. In a seroprevalence survey in animals in 1980 , antibodies to WNV were found in $8.8 \%$ of sheep, $8.7 \%$ of goats, $3.9 \%$ of cattle, $20.4 \%$ of horses, $1.4 \%$ of pigs, and $24.5 \%$ of birds [17]. In an unpublished survey conducted from May 2001 to December 2004,302 of 7,549 (4\%) equine serum samples were found positive for WNV using neutralisation tests; positive samples in equines were found in 36 of 49 districts (prefectures) studied from all parts of Greece $(0$. Mangana, Ministry of Agriculture, personal communication, 10 August 2010).

In conclusion, previous studies in humans and animals suggest that WNV has probably been circulating in the region of Central Macedonia and possibly in other parts of Greece for many years. Increased rainfall, high temperatures and humidity during recent months, as well as the geographical features (i.e. river deltas, rice 
fields, irrigated plains) of some parts of the region of Central Macedonia, have probably favoured the multiplication of Culex species, leading to the occurrence of numerous cases of WNV infection in humans.

\section{Public health measures}

After the initial notification of the cluster of WNV infection cases, the Hellenic Centre for Disease Control and Prevention alerted physicians throughout the country and prepared a set of guidelines for health professionals, with the necessary instructions for laboratory diagnosis. Surveillance of human WNV infection cases has been established and the public has been given guidance about personal protective measures.

The Hellenic Centre for Blood Transfusion prepared specific guidelines and measures for blood and blood products safety, including a 28-day deferral policy for all donors residing in the specific districts (prefectures) where WNV infection cases were detected, as well as any blood donor who had visited the same districts (prefectures) for one or more days. Blood units that had been collected in the same region since the beginning of July were quarantined until tested for WNV by PCR. They were all found negative for WNV and were released for use. Finally, specific advice was provided to all blood donors asking them to inform the blood donation department they attended, if they develop a fever within 15 days after their donation. The National Organisation for Transplantations has also been informed and is requesting WNV testing of donors depending on residence area or travel history.

The Ministry of Health and Social Solidarity coordinates the intensification of mosquito control programmes at district level, which are already being implemented. The Ministry also undertook the coordination of the health sector preparedness and the collaboration with the veterinary services of the Ministry of Agriculture. Surveillance for WNV in mosquitoes (using bait traps) has been put in place.

Updates on reported WNV infection cases and deaths in Greece are published in the daily epidemiological surveillance reports (available in English from http:// www.keelpno.gr/eng/wnv).

\section{Acknowledgements}

We would like to thank all hospital physicians and local public health authorities who contributed to the surveillance of WNV infections in Greece. The technical support of the personnel in the Reference Laboratory for Arboviruses in Thessaloniki is highly appreciated.

\section{References}

1. Burke D, Monath T. Flaviviruses. In: Knipe D, Howley P, editors. Fields virology 4 th ed. Philadelphia (PA): Lippincott Williams and Wilkins; 2001. p. 1043-126.

2. Hayes EB, Sejvar Jl, Zaki SR, Lanciotti RS, Bode AV, Campbel GL. Virology, pathology, and clinical manifestations of West Nile virus disease. Emerg Infect Dis. 2005 Aug;11(8):1174-9. Review.
3. Tsai TF, Popovici F, Cernescu C, Campbell GL, Nedelcu NI. West Nile encephalitis epidemic in southeastern Romania. Lancet. 1998;352(9130):767-71.

4. Briese T, Jia XY, Huang C, Grady LI, Lipkin WI. Identification of a Kunjin/West Nile-like flavivirus in brains of patients with New York encephalitis. Lancet. 1999;354(9186):1261-2.

5. Murgue B, Zeller H, Deubel V. The ecology and epidemiology of West Nile virus in Africa, Europe and Asia. Curr Top Microbiol Immunol. 2002;267:195-221.

6. Barzon L, Squarzon L, Cattai M, Franchin E, Pagni S, Cusinato $\mathrm{R}$, et al. West Nile virus infection in Veneto region, Italy, 2008-2009. Euro Surveill. 2009;14(31):pii=19289. Available from: http://www.eurosurveillance.org/ViewArticle. aspx?Articleld $=19289$

7. Rizzo C, Vescio F, Declich S, Finarelli AC, Macini P, Mattivi A, et al. West Nile virus transmission with human cases in Italy, August - September 2009. Euro Surveill. 2009;14(40):pii=19353. Available from: http://www. eurosurveillance.org/ViewArticle.aspx?Articleld=19353

8. Zeller HG, Schuffenecker I. West Nile virus: an overview of its spread in Europe and the Mediterranean basin in contrast to its spread in the Americas. Eur J Clin Microbiol Infect Dis. 2004 Mar;23(3):147-56.

9. Krisztalovics K, Ferenczi E, Molnar Z, Csohan A, Ban E, Zoldi V, et al. West Nile virus infections in Hungary, AugustSeptember 2008. Euro Surveill. 2008;13(45): pii=19030. Available from: http://www.eurosurveillance.org/viewarticle. aspx?articleid $=19030$

10. European Commission. Commission Decision of 28 April 2008 amending Decision 2002/253/EC laying down case definitions for reporting communicable diseases to the Community network under Decision No 2119/98/EC of the European Parliament and of the Council. 18.06.2008:L 159. Available from: http://ec.europa.eu/health/ph threats/com/ docs/1589_2008_en.pdf

11. Shi PY, Kauffman EB, Ren P, Felton A, Tai JH, Dupuis AP 2nd, et al. High-throughput detection of West Nile virus RNA. J Clin Microbiol. 2001;39(4):1264-71.

12. Sánchez-Seco MP, Rosario D, Domingo $C$, Hernández L, Valdés K, Guzmán MG et al. Generic RT-nested-PCR for detection of flaviviruses using degenerated primers and internal control followed by sequencing for specific identification. J Virol Methods. 2005;126(1-2):101-9.

13. Hellenic Statistical Authority (EL. STAT.). Mid-year estimated population by 5-year age groups level NUTS III (NOMOS). Population by usual residence. Pireus: EL. STAT. [Accessed 17 Jul 2010]. Available from: http://www.statistics.gr/ portal/page/portal/ver-1/ESYE/BUCKET/A1602/Other/ A1602_SPO18_TS_AN_00_1991_00_2007_08_F_EN.pdf

14. Antoniadis A, Alexiou-Daniel S, Malisiovas N, Doutsos I, Polyzoni T, Leduc JW, et al. Seroepidemiological survey for antibodies to arboviruses in Greece Arch Virol. 1990;Suppl $1: 277-85$.

15. Papa A, Perperidou P, Tzouli A, Castiletti C. West Nile virusneutralising antibodies in humans in Greece. Vector Borne and Zoonotic Dis. Epub 2010 Aug 25.

16. Kantzanou MN, Moschidis ZM, Kremastinou G, Levidiotou S, Karafoulidou A, Politis C, et al. Searching for West Nile virus (WNV) in Greece. Transfus Med. 2010;20:113-7.

17. Gratz NG. Vector- and rodent-borne diseases in Europe and North America. Distribution, public health burden, and control. Cambridge: Cambridge University Press; 2006. 